\title{
Experiment Teaching Reform for Software Engineering Majors Based On CDIO
}

\author{
CHEN Xiang ${ }^{1, a}$, QIU Ye $\mathrm{e}^{1, b}$ \\ ${ }^{1}$ Hangzhou Institute of Service Engineering, Hangzhou Normal University, Hangzhou, Zhejiang \\ Province, China \\ aflyingchen77@163.com, ${ }^{b}$ qiuye0120@163.com
}

Keywords: experiment teaching reform; CDIO; Software Engineering.

\begin{abstract}
In order to cultivate application oriented and high skilled talent $\mathrm{s}$ in the public education phase, it is essential for full development of students practice, design and innovation abilities by strengthening the experiment teaching. The CDIO(conceive, design, implement, operate) advocates learning by doing and project based education and learning. The CDIO theory is introduced in experiment teaching for software engineering majors, and experiment teaching is reformed based o $\mathrm{n}$ CDIO Syllabus. Specifically, a four level experiment system is designed, project based experiment contents are developed, and diversity evaluation methods are proposed. Through the new experiment teaching, students capacities as required by CDIO are fully trained to enhance students comprehensive quality.
\end{abstract}

\section{Introduction}

Traditional computer science training model, pay attention to theoretical contempt for practice, emphasis on individual academic ability while ignoring the spirit of teamwork [1]. People attach importance to knowledge learning underestimate innovation training, resulting in less ability to apply computer science graduates, the overall quality is not high, professionalism is not sufficient to meet the social, the actual needs. McKinsey Global Institute said "China's educational system is biased theory, almost no Chinese students by the actual project and team work training, and European and North American students in teams to solve practical problems" [2]. CDIO (conceive, design, implement, operate) is a new model for international engineering education today, by the Massachusetts Institute of Technology and the Swedish Royal Institute of Technology, four universities jointly initiated. This model is more emphasis on solid engineering basic theory and professional knowledge training, through each course, each module, each teaching to implement the ability the requirements of industry, to meet the quality professional requirements for construction industry. College of Engineering Shantou University, implemented the CDIO engineering education model in five undergraduate [3],Tsinghua University adopted CDIO teaching methods in the two courses "data structure" and "Database System Principles", these have achieved outstanding results [4]. Through the new model of teaching CDIO, students were generally enhanced self-learning ability, problem-solving skills, and research and development, communication skills and team work ability. Domestic and international experience shows, CDIO concept is scientific and feasible, is ideal for all aspects of the engineering teaching process. This paper will introduce the concept CDIO engineering education to computer science experimental curriculum, It is very important to train professional and technical capabilities and engineering capabilities of students.

\section{CDIO engineering education model}

CDIO is a new teaching model to promote "learning by doing" and "project-based education and learning”, It is a life-cycle as the carrier, works projects from research and development to run, allow students to take the initiative, practical, organic link between the way curriculum learning projects, the engineering ability of students, professional ethics, academic knowledge, apply knowledge to solve problems, life-long learning skills, teamwork skills, communication skills and a large the 
ability to control the system [5], to training both excellent professional skills, and good professional ethics of international engineers [6,7].

CDIO outline of Part 1 is about the engineering and technical knowledge, theory and technology, Part 2 is a personal and professional skills and characteristics, Part 3 is interpersonal skills, Part 4 is a business and social environment of the concept, design, implementation and operation of the system, in which personal and professional skills are essential core quality engineers. Students must master the appropriate technical knowledge and reasoning ability, in order to be able to work in a team environment, you must have the necessary interpersonal skills, have good communication skills, and finally, in order to truly create and run the product, system, students also must have from the enterprise, the social dimension to the idea, design, implementation and operation of products, systems.

Computer science courses students need to focus on not only the expertise of education, more importantly, students should pay attention to capacity-building engineering practice, students identify problems, analyze problems and problem-solving skills, training self-learning innovation and system analysis, design and implementation capacity. The ability training fully in line with the outline CDIO request. CDIO focus on practical teaching and practical ability, advocates experimental teaching should proceed from reality, and then rise to the theory, and finally back to practice, so as to create the final product and system for teaching purposes. In this theory, based on the CDIO concept in This paper will the experimental computer science courses were implemented, and make the appropriate changes.

\section{CDIO-based experimental teaching of computer science reform}

\section{1)Based on the experimental curriculum CDIO}

CDIO engineering education based on the concept, the experimental aspects of the product development life cycle concept, design, implementation and operation of closely integrated reference CDIO engineering education outline of the contents of the ability to design experiments for CDIO computer science curriculum, comprehensive training and ability of individual students, interpersonal communication skills, professional application capabilities, products and systems to build capacity, and demand for talent in the IT industry are consistent. Experimental curriculum can be broken down into four levels: the basic experiment, design of experiments, a comprehensive experimental and professional creative experiment.

Level 1 - basic experiment, the focus is to train students in related disciplines of basic laboratory skills, practices and ability to enhance the practice of awareness, deepen understanding of the theory of teaching content; 2nd level - design of experiments, is the foundation deep extension of the experiment, focusing on the mastery of professional skills, focusing on the students analyze and solve problems, and preliminary system analysis and design ability; 3rd level - a comprehensive experimental, technology-oriented jobs needs, focusing on the ability of students to professional applications, engineering reasoning and problem-solving ability; 4th level - Professional innovative experiment, focusing on students' teamwork, creative abilities, improve their theoretical ability to use and engineering practice.

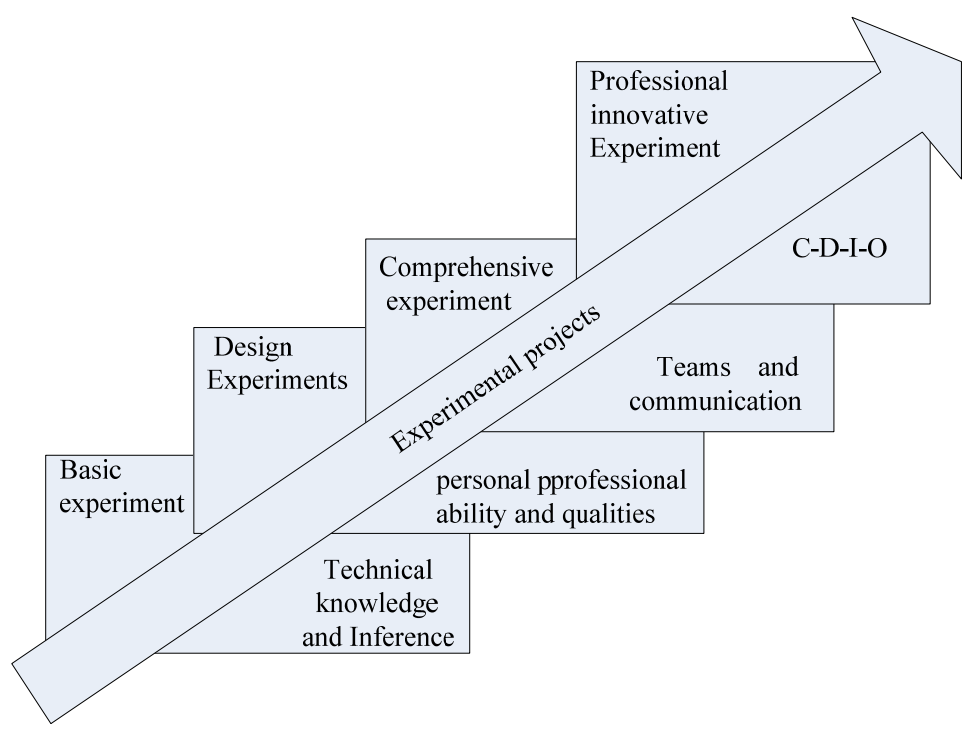

Fig. 1 the experimental curriculum based on CDIO

This experimental system of four 
levels, to promote the application of theory to the transformation of knowledge into the skills, individual skills to the overall quality of the conversion [8], better reflects the CDIO outline four types of capacity-building for students in the requirements (Fig. 1).

\section{2)Project-based content design experiments}

CDIO advocate "project-based education and learning." Design and implementation of the project is to train students to use the ability, capacity and quality of engineering an effective way, so the experiment should be designed to fully reflect the content of the project design ideas. At all levels of the experiment, a complete project as a case by case project the main contents throughout the experiment up, making the content of the experiment as an organic whole, and improve their practical interest, to improve the experimental results. In the specific implementation, the project will be the case for decomposition, the decomposition of these projects distributed throughout the experiment module. These projects are closely related to the module, after the previous experiment is an experiment in software infrastructure, in order to enable students to appreciate the continuity of system development [9]. For example, in "Web Programming" course of experimental teaching, through the design, realization of a press release distributed system to be closely linked to the experimental class. In the course of the first experiment, the system requires students to design the home page press release, the first two experiments, requiring students to use new knowledge of CSS for page formatting system news release. With the advance of theoretical courses, in learning the basic object of ASP, in the experiment requires students to use scripting language programming, news release system backend interface. In the study of the data access mechanism, the experimental class students will use to create a database link to access the object database, read and write data to achieve the system dynamic function of the news release. In this way, the students each experiment must be completed in the first case of an experiment carried out such an experiment designed to equip students with the concept of sustainability of the project.

\section{3)Based on "learning by doing" teaching method}

CDIO promote "learning by doing", emphasizing active learning [10]. Therefore, we should establish the "student-centered" concept in experiment, and guide the students to active learning.

In the design of experiments, before the experimental class the teachers assign the main task of the next experiment, ask students to combine their own progress of the project, and fully prepared. In the first 10 minutes of each experiment teaching, teachers review and resolve the important issues in the last experiment content and can also ask questions to understand the students' progress of the project. This is a link that can help students better knowledge of the previous review, and build links between new knowledge. As the experiment is the case for clues, in the atmosphere of the engineering practice, the sense of accomplishment of the project to encourage students to independent learning. The students themselves from the Internet to find information, positive thinking, analysis every step of the essentials in project implementation process, solve the problems during the project independently, cultivate students' ability to solve problems. After each experiment, student need to complete the experiment report.

The integrated design experiment is a group. The beginning of the project, students need to discuss. In the specific implementation, each member must not only carry out their tasks, but also to communicate and exchange with the students, every week a detailed progress report should be completed by the head of group. This experimental model will help train students on teamwork, communication skills with people.

\section{4)A wide range of evaluation methods}

CDIO claim the different ability to use assessment in different ways, create a variety of assessment methods. In order to scientifically and rationally assessment on the abilities of practical ability, communication and communication skills, problem-solving skills, teamwork and innovative ability of students, in the experimental program of the computer specialty appraisal, we have the following five aspects of assessment :

(1) Technical capability. Course teaching process and 10 experimental task-level project. 
(2) Engineering quality. The small projects development was completed by the database application system life cycle. Including requirements analysis, conceptual design, logical design, system implementation, project summary.

(3) Communication skills. Class project during the curriculum teaching, the respondent of curriculum design acceptance, the discussion in class.

(4) Team collaboration. Completion of curriculum design project, the division of labor and task completion of each member.

(5) Innovation capability. In curriculum design, students made the expansion in basic needs and the expansion in basis functions and their achievement.

These five aspects through classroom discussions, laboratory reports, project progress reports and project the completion situation, the four kinds of forms of assessment, and accordance with different weights included in the final results.

\section{Summary}

In order to change the traditional computer professional training model, this article draw on the CDIO engineering education philosophy, the design of the experimental teaching model suitable for the computer professional. project as a carrier In CDIO-based experimental teaching model, train students a variety of capacity that CDIO require, achieve seamlessly docking with computer science students, society and enterprise.

\section{Acknowledgements}

This work was partly supported by the teaching mode reform project of Hangzhou Normal University, the Hangzhou social development of scientific research projects NO.20120433B17 and Natural Science Foundation of Zhejiang Province NO.LQ12F02019.

\section{References}

[1] Ying hong. Team Approach [J]. Vocational Education Forum, 5,pp.14-15. (2009).

[2] Far rell D, Grant AJ. China slooming talent shortage [J/OL]. The McKinsey Quarterly, 4,pp.70-79. (2005). Http://www.mckinsyquarterly.com/article_page.aspx?ar = 1685.

[3] Kangquan Li, Lu Xiao-Hua, Xiong Guangjing. CDIO outline innovative training and engineering [J]. Higher Education Research, 31,4.pp.15-18. (2008).

[4] Li Manli. CDIO with historical interpretation and application prospects [J]. Tsinghua University Education Research, 29,5,pp.78-87. (2008).

[5] Zha Jianzhong. Investigation under construction. Engineering Education Reform Strategy CDIO and university-industry cooperation and international [J]. Chinese University of Education, 5,pp.16-19.(2008).

[6] Crawley EF, Malmqvist J, Ost lun dS.Rethinking Engineering Education The CDIO Approach [M]. New York: Springer, (2007).

[7] Crawley E. The CDIO Syllabus: A Statement of Goals for Undergraduate Engineering Education [G]. MIT CDIO Report \# 1, Dept of Aeronautics and Astronautics, Massachusetts Institute of Technology, Cambridge, MA, USA, (2001).

[8] Xu Bing, Sun Haiquan. TCDIO curriculum system and practice [J]. Higher Engineering Education and Research, 2, pp.35-38. (2009)

[9] Gu Xue-yong. CDIO linking theory and practice of Tsinghua University to explore innovative engineering education [J]. Higher Engineering Education and Research, 1,pp.11-23.(2009)

[10]Zha Jianzhong. On "learning by doing" strategy under the CDIO model [J]. Higher Engineering Education and Research, 3,pp.1-9(2008) 